\title{
Cost-effectiveness of one-stage versus two-stage breast reconstruction in the United Kingdom
}

\author{
Isabel Teo', Iman A. Azmy² \\ ${ }^{1}$ Department of Plastic Surgery, St John's Hospital at Howden, Livingston, West Lothian EH54 6PP, UK. \\ ${ }^{2}$ Department of Breast Surgery, Chesterfield Royal Hospital - NHS Foundation Trust, Calow, Chesterfield, Derbyshire S44 5BL, UK.
}

Address for correspondence: Miss. Isabel Teo, Department of Plastic Surgery, St John's Hospital at Howden, Livingston, West Lothian EH54 6PP, UK. E-mail: isabelteo@hotmail.com

\begin{abstract}
Aim: Permanent expanders allow for breast reconstruction as a single stage. These prostheses are more expensive than conventional tissue expanders, but this excess cost is markedly offset as only one operation is required. However, if the revision rate is sufficiently high, then this effect is negated. We aim to compare costs of one-stage vs. two-stage reconstruction at a single center, taking into account explantation and unexpected admissions following complications. Methods: A retrospective review was carried out on all patients who underwent one-stage and two-stage reconstruction over a 5 -year period by a single surgeon. A cost analysis was performed taking into account, explantation and additional admissions. Results: One hundred and forty-three one-stage and 45 two-stage procedures were included. The explantation rate for one-stage procedures is $36 \%$, at a mean of 12.9 months postimplantation, the majority of which were exchanged for silicone implants to improve cosmesis. Four (9\%) of the two-stage procedures were explanted a mean of 18 months postreconstruction. Overall, one-stage reconstructions were significantly more expensive than the two-stage group $(P=0.016)$. Conclusion: There are many benefits of one-stage breast reconstruction. However, it does not appear to be cost-effective when additional admissions for explantation surgery are taken into account.
\end{abstract}

Key words:

Breast reconstruction, cost-effectiveness, latissimus dorsi flap, McGhan ${ }^{\mathrm{TM}} 150$ expander implant, Natrelle $^{\mathrm{TM}} 150$ expander implant, one-stage breast reconstruction, permanent tissue expanders

\section{INTRODUCTION}

One-stage reconstruction was introduced in the 1980 s as a valuable addition to the breast reconstruction armamentarium. The first expander implant, the Becker ${ }^{\mathrm{TM}}$ Siltex, ${ }^{[1]}$ came onto the market in 1984 , this is a round prosthesis with a saline-filled inner lumen surrounded by a silicone gel, connected to a remote port for injection of saline. These implants provide the volume flexibility

\begin{tabular}{|l|l|}
\hline \multicolumn{2}{|c|}{ Access this article online } \\
\hline Quick Response Code: & Website: \\
\hline & www.parjournal.net \\
\cline { 2 - 2 } & \\
\hline & \\
\hline
\end{tabular}

of a saline implant and permit long-term, noninvasive adjustment of breast size. Reconstruction can, therefore, be completed as a single procedure. The implant is placed at the index procedure, expansion achieved with repeat outpatient injections of saline until optimum breast size is reached. The traditional two-stage reconstruction, however, involves two operations, the first involving the

This is an open access article distributed under the terms of the Creative Commons Attribution-NonCommercial-ShareAlike 3.0 License, which allows others to remix, tweak, and build upon the work non-commercially, as long as the author is credited and the new creations are licensed under the identical terms.

\section{For reprints contact: reprints@medknow.com}

How to cite this article: Teo I, Azmy IA. Cost-effectiveness of onestage versus two-stage breast reconstruction in the United Kingdom. Plast Aesthet Res 2015;2:320-5.

Received: 03-01-2015; Accepted: 24-09-2015 
insertion of the expander and the second to exchange the expander for a fixed volume silicone implant, once the expander has reached its ideal size after outpatient injections. ${ }^{[2]}$

The Natrelle ${ }^{\mathrm{TM}} 150$ (previously known as the McGhan ${ }^{\mathrm{TM}} 150$ ) was introduced in the 1990s. Like the Becker Siltex, it has an inner chamber of saline outer shell of silicone, and a remote port. The main difference is that the Becker Siltex is round, while the Natrelle ${ }^{\mathrm{TM}} 150$ has an anatomical shape, purportedly creating a more natural, teardrop shape. At present, the Natrelle ${ }^{\mathrm{TM}} 150$ and Becker $^{\mathrm{TM}}$ range are the only two expander implants on the market, available for one-stage reconstruction, and the Natrelle $^{\mathrm{TM}} 150$ is routinely used at our unit for one-stage reconstruction.

The surgical outcomes of the Natrelle ${ }^{\mathrm{TM}} 150$ expander are well known, with many papers endorsing its good surgical outcomes..$^{[3-6]}$ However, it is more expensive than a comparative tissue expander [Table 1], but deemed to be cost-effective with many savings derived from a one-stage operation.

The corollary to this is that any unexpected complication resulting in loss or exchange of the implant will effectually result in a two-stage operation. This will incur the cost of a second hospital admission, general anesthetic procedure, and additional implant over and above the excess material cost of the Natrelle ${ }^{\mathrm{TM}} 150$ implant. There is increasing emphasis on good health economics, and to date there has been no cost analysis study analyzing if expander implants are truly cost-effective.

To analyze the costs of one-stage and two-stage breast reconstructions, taking into account unexpected explantation as a complication. This will allow us to evaluate the true cost-effectiveness of one-stage reconstruction at a single institution in the UK.

\section{METHODS}

A retrospective case note review was carried out on all patients who had undergone one-stage and two-stage at our unit from 2005 to 2010 by a single oncoplastic surgeon. The Natrelle ${ }^{\mathrm{TM}} 150$ implant is utilized in our hospital for one-stage reconstruction, and the Mentor ${ }^{\mathrm{TM}}$ Siltex and Allergan $^{\mathrm{TM}} 133$ expanders for two-stage reconstruction. All the patients received a drain in the breast pocket and remained in hospital until the drains are removed. We do not employ the use of dermal substitutes such as Strattice ${ }^{\mathrm{TM}}$. All patients who underwent one-stage and two-stage reconstruction were included in our database, and there was no exclusion criterion.

Cost information was obtained from the financial department and surgical directorate accountant. Each procedure is assigned a Healthcare Resource Group (HRG) ${ }^{[7 \mid}$ code which determines the costs incurred. Within the National Health Service (NHS), a HRG is a group consisting of patient events that have been deemed to consume a similar level of resource. This cost is based on a maximum number of days staged as an inpatient, after which each night will incur an excess cost of $£ 131$. This is shown in Table 2 .

Using this method of data analysis, we analyzed length of stay and costs incurred in all four procedure groups: the Natrelle ${ }^{\mathrm{TM}} 150$ only procedure group; the Natrelle ${ }^{\mathrm{TM}} 150$ and latissimus dorsi (LD) procedure group; the Allergan ${ }^{\mathrm{TM}} 133$ procedure group and Mentor ${ }^{\mathrm{TM}}$ Siltex procedure group. We specifically calculated the average costs and length of stay for retained and explanted procedures.

Nonparametric data were analyzed using Chi-squared and Fisher's exact tests. Cost was analyzed using independent sample $t$-test, Kruskal-Wallis and Mann-Whitney $U$-tests. SPSS version-20 was used for all statistical analysis with the assistance of a trust-affiliated statistician.

\section{RESULTS}

One hundred and forty-three one-stage procedures and 45 two-stage procedures were performed. All patients' demographics oncological histology, and treatment by procedure are shown in Table 3. Chi-squared analysis and Fisher's exact test were used to compare parameters between these groups. We found that there were a significantly higher number of patients in the one-stage reconstruction group who received radiotherapy compared to the two-stage reconstruction group $(P<0.01)$. This observation is expected as patients who have had radiotherapy are more likely to have a LD flap procedure. It is the senior author's practice to offer permanent expanders in patients who require LD flaps. This allows for greater volume to match the contralateral side and also allows for future alterations, given the unpredictable

Table 1: Typical costs of implants in the UK

\begin{tabular}{lc}
\hline Reconstruction & Cost \\
\hline One-stage reconstruction & \\
Natrelle $^{\text {TM }} 150$ & $£ 975$ \\
Two-stage reconstruction & \\
Expander & $£ 599$ \\
Fixed volume implant & $£ 560$ \\
Total & $£ 1,159$ \\
\hline
\end{tabular}

Table 2: Procedures and stipulated costs according to HRG codes

\begin{tabular}{lc}
\hline Procedure & $\begin{array}{c}\text { Cost and maximum number } \\
\text { of days of inpatient stay }\end{array}$ \\
\hline Natrelle $^{\mathrm{TM}}$ 150 only reconstruction & $£ 3,402$ \\
Natrelle $^{\mathrm{TM}}$ 150 + LD reconstruction & 14 days \\
& $£ 3,402$ \\
Allergan $^{\mathrm{TM}} 133$ first stage & 14 days \\
reconstruction $^{\mathrm{TM}}$ Siltex first stage & $£ 1,148$ \\
Mentor $^{\mathrm{T}}$. & 63 days \\
reconstruction $_{\text {Exchange of expander/expander }}$ & 14 days \\
implant for fixed volume implant & $£ 1,236$ \\
\hline
\end{tabular}

Additional inpatient stay would incur a daily rate of $£|3|$. LD: Latissimus dorsi, HRG: Healthcare Resource Group 
Table 3: Patient demographics tumor histology and oncological treatment by procedure

\begin{tabular}{|c|c|c|c|c|}
\hline & Natrelle $^{\mathrm{TM}} 150$ only (\%) & Natrelle $^{\mathrm{TM}} 150$ + LD (\%) & Allergan ${ }^{\mathrm{TM}} 133(\%)$ & Mentor ${ }^{\mathrm{TM}}$ Siltex (\%) \\
\hline Number of patients & 34 & 92 & 21 & 11 \\
\hline Frequency of procedures & 45 & 98 & 28 & 17 \\
\hline Mean age at implantation & $52.6(20-73)$ & $51.3(24-68)$ & $49.4(21-68)$ & $48.9(30-61)$ \\
\hline Mean BMI & $28.0(21-43)$ & $25.7(18-43)$ & $27.9(18-38)$ & $24.5(21-30)$ \\
\hline Smokers & $7(21)$ & $11(12)$ & $2(9.5)$ & $1(9.1)$ \\
\hline Diabetes & 0 & $2(2.2)$ & $1(4.8)$ & 0 \\
\hline \multirow[t]{4}{*}{ ASA } & $1=13(38)$ & $1=46(50)$ & $1=12(57)$ & $1=4(36)$ \\
\hline & $2=19(56)$ & $2=42(46)$ & $2=9(43)$ & $2=7(64)$ \\
\hline & $3=2(5.9)$ & $3=2(2.2)$ & $3=0$ & $3=0$ \\
\hline & $4=0$ & $4=0$ & $4=0$ & $4=0$ \\
\hline \multicolumn{5}{|l|}{ Tumor } \\
\hline DCIS & $21(47)$ & $53(54)$ & $13(47)$ & $10(59)$ \\
\hline Invasive & $28(62)$ & $74(76)$ & $15(54)$ & $14(82)$ \\
\hline NPI range & $2.14-6.56$ & $2.06-7.20$ & $2.22-5.52$ & $2.01-5.50$ \\
\hline Radiotherapy & $2(4.5)$ & $25(26)$ & 0 & 0 \\
\hline Chemotherapy & $19(42)$ & $38(39)$ & $10(36)$ & $10(59)$ \\
\hline Hormonal & $21(15)$ & $66(67)$ & $14(50)$ & $11(65)$ \\
\hline Neoadjuvant & 0 & $4(4.1)$ & 0 & 0 \\
\hline Herceptin & $3(2.1)$ & $8(8.2)$ & 0 & $1(5.9)$ \\
\hline
\end{tabular}

LD: Latissimus dorsi, BMI: Body mass index, ASA: American Society of Anaesthesiologists, DICS: Ductal carcinoma in situ, NPI: Nottingham prognostic index

degree of LD atrophy that can ensue. Analyzing all the other factors, there was no statistical significant difference between the one-stage procedure group and two-stage procedure group $(P>0.05)$. There were insufficient patients with diabetes to make a valid analysis on this parameter. A Cox regression analysis found that age, body mass index, smoking status, radiotherapy, and American Society of Anaesthesiologist grades were not significantly associated with higher rates of explantation.

\section{Explantation}

Explantation is the unanticipated removal or exchange of implants secondary to complications. Fifty-one (36\%) of the Natrelle ${ }^{\mathrm{TM}} 150$ implants were explanted an average of 12.9 months after implantation (range: 1-48 months, median: 8.0 months). The majority $(40,79 \%)$ were exchanged for fixed volume silicone implants to improve esthetics. Other indications were infection $(5,9.8 \%)$, leak $(2,3.9 \%)$ and recurrence of cancer $(4,7.8 \%)$.

In the two-stage reconstruction group, problems can likewise develop requiring implant removal or exchange with cost implications. Explantation of the final fixed volume silicone implants was analyzed. In the Mentor $^{\mathrm{TM}}$ Siltex group, one implant was exchanged for another prosthesis, 18 months later due to implant migration. In the Allergan ${ }^{\mathrm{TM}} 133$ group, three implants were exchanged to improve cosmesis, an average of 19 months after their second stage procedure.

\section{Cost analysis}

Forty percentage of Natrelle ${ }^{\mathrm{TM}} 150$ only implants were retained with an average length of inpatient stay of 3.78 days gives an average cost of $£ 3,422$, close to the estimated HRG stipulated cost of $£ 3,402$. However, $60 \%$ of the Natrelle ${ }^{\mathrm{TM}} 150$ only implants were explanted with an average total inpatient stay of 4.22 days. There was a mean unanticipated excess cost of $£ 1,350$ in each of these explanted implants, with the cost of each patient $£ 4,755$ instead of the stipulated $£ 3,402$. Similar analyses have been performed for the Natrelle ${ }^{\mathrm{TM}} 150$ and LD group, Allergan $^{\mathrm{TM}} 133$ and Mentor ${ }^{\mathrm{TM}}$ Siltex groups [Figure 1].

Overall cost was analyzed using a Kruskal-Wallis test (nonparametric equivalent of an ANOVA) and Mann-Whitney $U$-test. This shows that the Allergan ${ }^{\mathrm{TM}} 133$ two-stage procedure is the cheapest reconstructive option $(P<0.001)$. The Mentor ${ }^{\mathrm{TM}}$ Siltex and Natrelle ${ }^{\mathrm{TM}} 150$ only procedure are the most expensive options. We used an independent sample $t$-test to compare the combined overall costs of the one-stage procedures to the two-stage procedures and this showed that the one-stage group was significantly more expensive than the planned two-stage group $(P=0.016)$.

\section{DISCUSSION}

While the material costs of the Natrelle ${ }^{\mathrm{TM}} 150$ is more expensive than its comparative expander or silicone implant, it is thought to be cost-effective as it eliminates the expenses associated with a second operation. However, any complication resulting in the loss or exchange of this implant will essentially convert a one-stage procedure into a two-stage operation. This includes the additional costs of a second general anesthetic procedure and replacement of the implant in addition to the original costs of the Natrelle ${ }^{\mathrm{TM}} 150$ implant. In today's health economics, where health care providers are increasingly required to rationalize expenses, these cost implications merit investigation.

There are a growing number of studies analyzing the costs of various breast reconstructions. ${ }^{[8-11]}$ Grover et al. ${ }^{[12]}$ compared five methods of breast reconstruction-autologous flaps with pedicled tissue, autologous flaps with free 


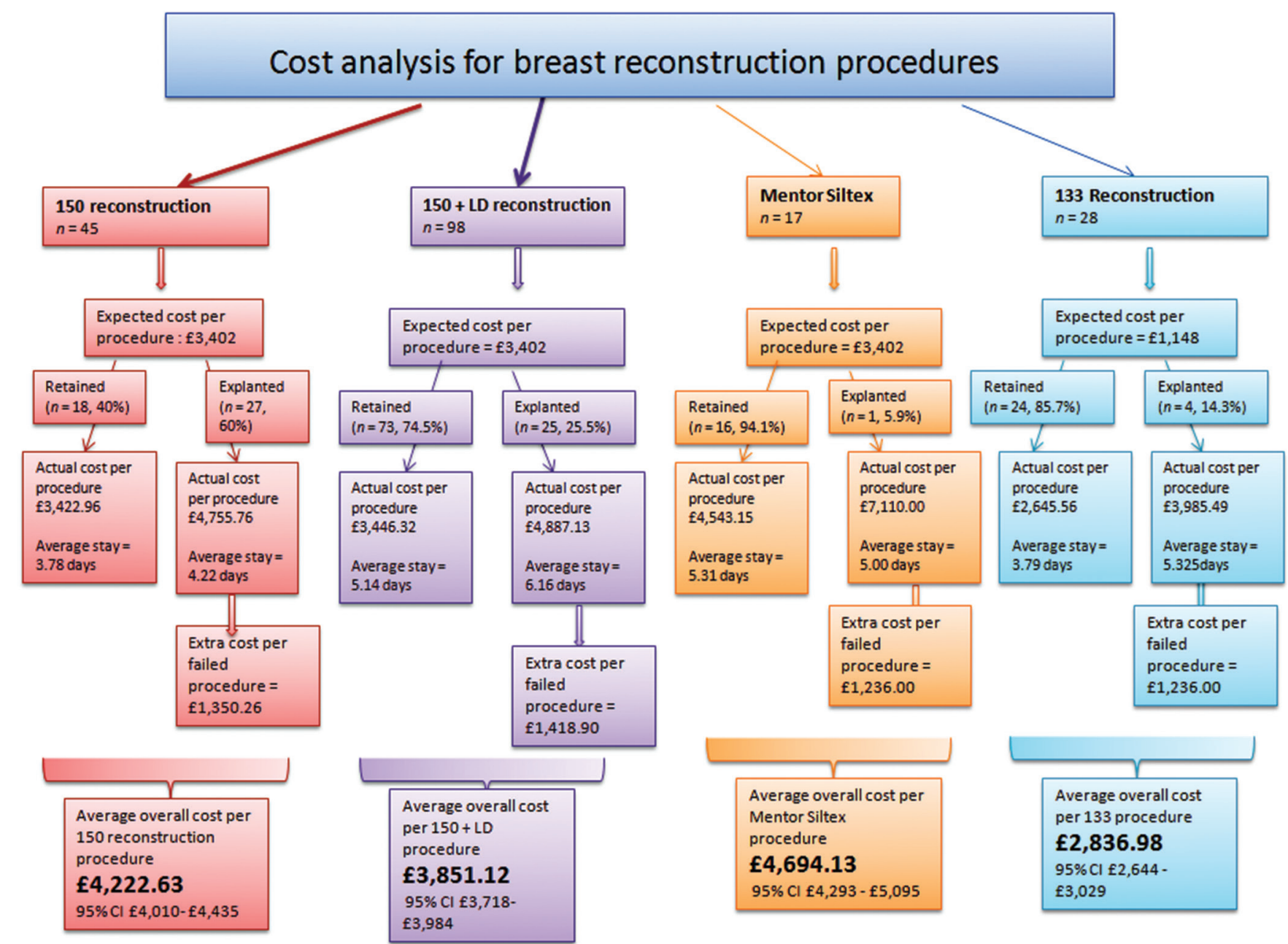

Figure 1: The costs incurred for each type of reconstruction when additional admissions and surgery secondary to explantation are taken into account

tissue, LD flaps with breast implants, expanders with implant exchange and immediate implant placement. They concluded "that autologous pedicled tissue was slightly more cost-effective than free tissue reconstruction", and that "implant based techniques were not cost-effective". Damen et al. ${ }^{[13]}$ compared silicone implants, implants preceded by tissue expansion, LD flaps and deep inferior epigastric perforator flaps in 427 patients in a single Dutch center. They found that immediate one-stage reconstructions have lower costs compared with flap procedures and tissue expander reconstructions. To date, there have been no cost analysis solely comparing one-stage and two-stage reconstruction.

At present, there are only two expander implants on the UK market designed for a one-stage reconstruction: the Natrelle $^{\mathrm{TM}} 150$ and the Becker ${ }^{\mathrm{TM}}$ Siltex. The Natrelle ${ }^{\mathrm{TM}}$ 150 implant is used for one-stage reconstruction at this center because the surgeon has been trained in its use and is most familiar with this product. There is no clear benefit of using one expander implant over the other apart from surgeon or patient preference. In fact, a paper ${ }^{[14]}$ published in November 2010 compared aesthetic outcome and patient satisfaction between patients who had received the Natrelle ${ }^{\mathrm{TM}} 150$ implant and Becker Siltex implant. Two groups of patients who were all undergoing bilateral, prophylactic mastectomy and immediate reconstruction were randomly assigned to either the Natrelle ${ }^{\mathrm{TM}} 150$ or Becker ${ }^{\mathrm{TM}}$ Siltex implant. Aesthetic outcomes were evaluated by an expert panel who also tried to recognize which implants the breasts were reconstructed with. The results showed that there was no difference between the two groups in terms of symmetry, outcome scores and patient satisfaction. The expert panel guessed the right implant shape in $42 \%$ of the Natrelle ${ }^{\mathrm{TM}}$ 150 implants and $66 \%$ of the round implants.

There have been a number of studies ${ }^{[15-18]}$ assessing survival of the Becker ${ }^{\mathrm{TM}}$ permanent expanders with variable results. Taboada-Suarez et al. ${ }^{[19]}$ reviewed 314 Becker $^{\text {TM }}$ permanent expander's implants in 237 patients, and found "a mean survival time to explantation of 120 months". Farace et al. ${ }^{[20 \mid}$ found that 77 of Becker $^{\mathrm{TM}}$ implants were removed within 5 years in a cohort of 99 patients. Goh et al. ${ }^{[21]}$ found an explantation rate of $25 \%$ at a mean follow-up of 64.6 months. There is much less published data on the longevity of the Natrelle ${ }^{\mathrm{TM}} 150$ implant. Gui et al. ${ }^{[22]}$ studied 107 patients with 129 reconstructions with the Natrelle ${ }^{\mathrm{TM}} 150$ and found a low $3.9 \%$ explantation rate at a mean of 18 months. Cicchetti et al. ${ }^{[4]}$ analyzed 97 consecutive patients who received a 107 Natrelle $^{\mathrm{TM}}$ 150 expander implants and their data show an overall explantation rate of $25 \%$ by 6 years. Despite its primary design of permanent expanders being "permanent", 
it is evident from the growing literature that these expander implants are often removed early secondary to complications. Eriksen et al. ${ }^{[23]}$ performed a prospective, randomized study comparing one-stage (Becker 25) and two-stage reconstruction and found that $70 \%$ in the one-stage group required revision surgery. They concluded that "the permanent expander method failed significantly as a one-stage procedure". Similarly, Susarla et al. ${ }^{[24]}$ compared one-stage and two-stage reconstructions and found that the one-stage cohort was " $80 \%$ more likely to require additional operative revisions" compared to the two-stage group. This is an important consideration not only for economic reasons, but also for patient selection and counseling.

Explantation is the most objective, measurable complication and we looked at this in detail. Our data show an overall explantation rate of $36 \%$ at a mean of 12.9 months postimplantation. These results suggest that for a significant proportion of patients undergoing planned one-stage reconstruction, the Natrelle $^{\mathrm{TM}} 150$ has functioned as a temporary expander.

Our analysis of costs involved revealed some surprising findings, in particular, the operation codes, HRG codes and allocated costs. Vastly differing procedures, while using different implants with different expected operating time, are given the same HRG code and costs. For example, the LD and Natrelle ${ }^{\mathrm{TM}} 150$ expander procedure has the same code as the Natrelle ${ }^{\mathrm{TM}} 150$ only procedure, despite the former being much more technically demanding, involving a significantly longer operating time and inpatient hospital stay. The Natrelle ${ }^{\mathrm{TM}} 150$ only procedure and the Natrelle ${ }^{\mathrm{TM}}$ Siltex procedure similarly have the same coding, despite the Natrelle ${ }^{\text {TM }} 150$ implant being approximately twice the price of the Natrelle ${ }^{\mathrm{TM}}$ Siltex implant and the operation itself being almost identical.

From our discussions with the financial team, many procedures are clustered together under the same coding umbrella as this simplifies costs for the thousands of operations performed in the NHS. Money saved in one operation might be used to cover the excess costs of another operation with underestimated costs. Similar grouping of operations was observed in another hospital in the same region.

We have been very specific in our cost analysis, which only looks at the tariffs and costs of the index procedure length of inpatient stay and explantation as a complication. The benefits of this analysis are relative, simplicity and speed of data acquisition. As mentioned before, the explantation is an objective, measurable complication, and its costs are easy to quantify with a defined HRG code and designated cost.

However, our cost analysis does not accurately represent the overall cost for each patient. We have not included any contralateral procedures such as augmentation, mastopexy or reductions, or subsequent procedures on the ipsilateral side such as nipple reconstruction or tattooing. We have not included outpatient visits, medications, physiotherapy or any unexpected costs from complications other than explantation. It is not feasible to factor in these additional costs based on a retrospective study. We are interested in the rates of explantation and the cost implications resulting from failed one-stage procedure. Our results show that the cost of one-stage reconstruction at this center is significantly more expensive than two-stage reconstruction.

Cost implications of varying breast reconstructions are an important subject worthy of study and results are highly relevant to clinical practice. While our methodology for cost analysis is objective and transferable, we question if the results reflect the true costs in clinical practice, given the way the coding system is derived.

This is the first study to directly compare the cost of one-stage versus two-stage breast reconstruction. We have found that the one-stage procedure is significantly more expensive than two-stage reconstruction. This is based on a $36 \%$ explantation rate, which is comparable to other series showing explantation rates ranging from $25 \%$ to $70 \%$. There are many benefits of one-stage breast reconstruction; however, it does not appear to be cost-effective when additional admissions for explantation surgery are taken into account.

\section{Financial support and sponsorship Nil.}

\section{Conflicts of interest}

There are no conflicts of interest.

\section{REFERENCES}

I. Becker $\mathrm{H}$. Breast reconstruction using an inflatable breast implant with detachable reservoir. Plast Reconst Surg 1984;73:678-83.

2. Woods JE, Mangan MA. Breast reconstruction with tissue expanders: obtaining an optimal result. Ann Plast Surg 1992;28:390-6.

3. Munhoz AM, Aldrighi C, Montag E, Arruda EG, Aldrighi JM, Filassi JR, Ferreira MC. Periareolar skin-sparing mastectomy and latissimus dorsi flap with biodimensional expander implant reconstruction: surgical planning, outcome, and complications. Plast Reconstr Surg 2007; 1 19:1637-49.

4. Cicchetti S, Leone MS, Franchelli S, Santi PL. One-stage breast reconstruction using McGhan Style I 50 biodimensional expanders: a review of 107 implants with six years experience. J Plast Reconstr Aesthet Surg 2006;59:1037-42.

5. Salgarello M, Seccia A, Eugenio F. Immediate breast reconstruction with anatomical permanent expandable implants after skin sparing mastectomy: aesthetic and technical refinements. Ann Plast Surg 2004;52:365-6.

6. Mandrekas AD, Zambakos G], Katsantoni PN. Immediate and delayed breast reconstruction with permanent tissue expanders. Br J Plast Surg 1995;48:572-8.

7. Health and Social Care Information Centre. Healthcare Resource Groups (HRGs). National Health Service-Connecting for Health. CUK 20II. Available from: http://www.hscic.gov.uk/article/232I/HRG4 -200809-Reference-Costs-Grouper-Documentation. [Last accessed on 2015 Jan 0I].

8. Johnson RK, Wright CK, Gandhi A, Charny MC, Barr L. Cost minimisation analysis of using acellular dermal matrix (Strattice ${ }^{\mathrm{TM}}$ ) for breast reconstruction compared with standard techniques. Eur J Surg Oncol 2013;39:242-7.

9. Fischer JP, Sieber B, Nelson JA, Cleveland E, Kovach SJ, Wu LC, Kanchwala S, Serletti JM. Comprehensive outcome and cost analysis of free tissue transfer for breast reconstruction: an experience with 1303 flaps. Plast Reconstr Surg 2013;|31:195-203.

10. Singh NK, Reaven NL, Funk SE. Cost comparison of immediate one-stage and tissue-expander breast reconstructions after mastectomy in commercially insured patients. Manag Care 2013;22:36-43. 
II. Krishnan NM, Chatterjee A, Rosenkranz KM, Powell SG, Nigriny JF, Vidal DC. The cost-effectiveness of acellular dermal matrix in expander-implant immediate breast reconstruction. J Plast Reconstr Aesthet Surg 20|4;67:468-76.

12. Grover R, Padula WV, Van Vliet M, Ridgway EB. Comparing five alternative methods of breast reconstruction surgery: a cost-effectiveness analysis. Plast Reconstr Surg 2013;132:709e-23e.

13. Damen TH, Wei W, Mureau MA, Tjong-Joe-Wai R, Hofer SO, Essink-Bot ML, Hovius SE, Polinder S. Medium-term cost analysis of breast reconstructions in a single Dutch centre: a comparison of implants, implants preceded by tissue expansion, LD transpositions and DIEP flaps. J Plast Reconstr Aesthet Surg 201 1;64:1043-53.

14. Gahm J, Edsander-Nord A, Jurell G, Wickman M. No differences in aesthetic outcome or patient satisfaction between anatomically shaped and round expandable implants in bilateral breast reconstruction: a randomized study. Plast Reconst Surg 2010;126:1419-27.

15. Sindali K, Davis M, Mughal M, Orkar KS. The natural history of Becker expandable breast implants: a single-center 10 -year experience. Plast Reconstr Surg 20 I3; I32:345e-5 I e.

16. Becker $\mathrm{H}$. The expandable mammary implant. Plast Reconstr Surg 1987;79:63।-7.

17. Calmilleri IG, Malata CM, Starvrianos S, McLean NR. A review of I 20 Becker permanent tissue expanders in reconstruction of the breast. Br J Plast Surg |996;49:346-5I.

18. Scuderi N, Alfano C, Campus GV, Rubino C, Chiummariello S, Puddu A,
Mazzocchi M. Multicenter study on breast reconstruction outcome using becker implants. Aesthetic Plast Surg 201 1;35:66-72.

19. Taboada-Suarez A, Brea-García B, Magán-Muñoz F, Couto-González I, González-Álvarez E. Risk factors associated with complication rates of becker-type expander implants in relation to implant survival: review of 314 implants in 237 patients. Ann Plast Surg 2014;4.

20. Farace F, Faenza M, Bulla A, Rubino C, Campus GV. Is mammary reconstruction with the anatomical Becker expander a simple procedure? Complications and hidden problems leading to secondary surgical procedures: a follow-up study. J Plast Reconstr Aesthet Surg 2013;66:74I-6.

21. Goh SC, Thorne AL, Williams G, Laws SA, Rainsbury RM. Breast reconstruction using permanent Becker expander implants: an 18 year experience. Breast 20I2;21:764-8.

22. Gui GP, Tan SM, Faliakou EC, Choy C, A'Hern R, Ward A. Immediate breast reconstruction using biodimensional anatomical permanent expander implants: a prospective analysis of outcome and patient satisfaction. Plast Reconstr Surg 2003; I I : I 25-38.

23. Eriksen C, Lindgren EN, Frisell J, Stark B. A prospective randomized study comparing two different expander approaches in implant-based breast reconstruction: one stage versus two stages. Plast Reconstr Surg 20I2; I30:254e-64e.

24. Susarla SM, Ganske I, Helliwell L, Morris D, Eriksson E, Chun YS. Comparison of clinical outcomes and patient satisfaction in immediate single-stage versus two-stage implant-based breast reconstruction. Plast Reconstr Surg 20I5; I35:Ie-8e. 